\title{
Sonographic BI-RADS ${ }^{\circledR}$ : analysis of initial results
}

\author{
BI-RADS ${ }^{\circledR}$ ultrassonográfico: análise de resultados iniciais
}

Fernanda Philadelpho Arantes Pereira*

The role of ultrasonography has expanded as a relevant method in the diagnosis of breast diseases. Besides diagnosing palpable lesions that could not be seen at mammography, particularly in patients with dense breasts, ultrasonography is useful in the characterization of cystic lesions and in the differentiation between benign and malignant masses. Also, it is an effective tool for guidance of interventional procedures. The developments of diagnostic and interventional ultrasonography play an essential role in the improvement of breast cancer management and prognosis.

Considering that this method is operator-dependent, the mandatoriness of professional skills and experience is clear, in order to allow not only the images visualization and interpretation, but also the utilization of a standardized classification system based on the morphological characteristics of the lesion. The standardization of terms for lesion characterization and reporting presents several advantages: increased reliability in the images interpretation and classification, the patients follow-up is facilitated, improvement of the dialogue between radiologists and referring physicians, creation of a tool for auditing breast radiology centers, besides allowing the development of a database for elaboration of epidemiological studies.

Recognizing the necessity of increasing the clinical effectiveness of breast ultrasonography, the American College of Radiology (ACR) has developed the BI-RADS ${ }^{\circledR}$, consisting of a breast imaging lexicon and a system for reporting standardization. The standardized terminology and assessment categories allow a clear synthesis of the imaging findings description, guiding the radiologist towards a less intuitive and more objective diag-

\footnotetext{
* Fellow Master Degree in Radiology, Faculdade de Medicina da Universidade Federal do Rio de Janeiro (UFRJ), MD, Radiologist at Department of Breast - Clínica de Diagnóstico Por Imagem (CDPI), Rio de Janeiro, RJ, Brazil. E-mail: fephila@gmail.com
}

nostic impression, as well as the referring physician towards a defined clinical conduct compatible with the degree of suspicion and malignancy of the lesion.

The fourth edition of the BI-RADS for mammography was published in $2003^{(1)}$ in association with the first BI-RADS edition for ultrasonography and magnetic resonance imaging. In Brazil, the Colégio Brasileiro de Radiologia (CBR) adapted the BI-RADS in $2005^{(2)}$, in accordance with specific Portuguese language characteristics.

In the original article, "Accuracy of sonographic findings in breast cancer: correlation between BI-RADS ${ }^{\circledR}$ categories and histological findings" (3), included in the present issue of Radiologia Brasileira, the authors have observed $70 \%-83 \%$ sensitivity in the detection of malignant lesions by ultrasonography utilizing the BIRADS classification. Like in other studies in the literature ${ }^{(4)}$, the negative predictive value of the BI-RADS category 3 was high, corroborating the usefulness of this tool to avoid unnecessary biopsies. The sonographic identification of probably benign masses eligible for a short-term follow-up requires the ruling out of any sign of malignancy and the presence of a set of benignity criteria.

However, according to the same article included in the present issue ${ }^{(3)}$, the BI-RADS has presented a low specificity (between 55\% and 56\%), for the sonographic diagnosis of breast cancer, because of the high number of false-positive results. The positive predictive value for categories 4 and 5 was lower than $50 \%$, which may be related both to the overlap of sonographic features of malignant and benign lesions in category 4 and inappropriate classification of lesions into BI-RADS 4 instead of BI-RADS 3, leading to the performance of unnecessary biopsies.

The overall interobserver agreement, reported as moderate in the mentioned article ${ }^{(3)}$, and as variable in 
the literature ${ }^{(5,6)}$, suggests that an appropriate technical uniformity is still to be achieved among radiologists in the BI-RADS characterization and classification of lesions.

Differently from the BI-RADS lexicon for mammography, the ultrasonography lexicon is still recent and with few related publications. Thus, a tested and proved quality program involving equipment and practitioners in the utilization of the sonographic BI-RADS is still pending ${ }^{(7)}$. In this way, the literature shows controversy in relation to the predictive value of each sonographic finding for the diagnosis of malignancy or benignity of breast masses. A consensus is still to be reached about which sonographic characteristics would be more relevant, less subjective and more reproducible. Individually, shape, margins and orientation are the criteria most frequently highlighted by different studies ${ }^{(4,8,9)}$, the one published in the present issue of Radiologia Brasileira ${ }^{(3)}$, inclusive, as the most relevant criteria to be taken into consideration in the differentiation between malignant and benign masses. On the other hand, echogenicity and posterior echotransmission of lesions present variable results in the literature ${ }^{(4,8,9)}$. However, when combined, characteristics such as irregular shape, noncircumscribed margins, posterior acoustic shadowing and non-parallel orientation in relation to the skin axis present a high predictive value for malignancy, many times favoring the classification of a lesion as BI-RADS 5.

Finally, there are two key issues directly related to the improvement of BI-RADS results and, consequently, to the continuation of developments in diagnostic breast ultrasonography: 1) training of radiologists involved in breast imaging and utilization of the sonographic BI-RADS, with systematic cases review and correlation of images with the pathology, and updat- ing courses on BI-RADS; 2) updating of the sonographic BI-RADS lexicon, based on recent studies, with a better definition of the role played by individual or combined findings in the differentiation between malignant and benign masses, as well as the suggested classification based on such findings.

As regards future prospects, some studies ${ }^{(8)}$ suggest the application of quantitative methods, computer-aided diagnostics (CAD)-type systems, in the analysis of breast tumors contours and texture, reducing the influence of the radiologist subjectivity on the classification of lesions. These methods would be a powerful auxiliary tool in the sonographic diagnosis of breast masses.

\section{REFERENCES}

1. American College of Radiology. Breast Imaging Reporting and Data System, atlas. 4th ed. Reston: American College of Radiology; 2003.

2. Colégio Brasileiro de Radiologia. BI-RADS - Sistema de laudos e registro de dados de imagem da mama. São Paulo: Colégio Brasileiro de Radiologia; 2005.

3. Nascimento JHR, Silva VD, Maciel AC. Acurácia dos achados ultrassonográficos do câncer de mama: correlação da classificação BI-RADS ${ }^{\circledR}$ e achados histológicos. Radiol Bras. 2009;42: 235-40.

4. Roveda Jr D, Piato S, Oliveira VM, et al. Valores preditivos das categorias 3, 4 e 5 do sistema BI-RADS em lesões mamárias nodulares não-palpáveis avaliadas por mamografia, ultra-sonografia e ressonância magnética. Radiol Bras. 2007;40:93-8.

5. Raza S, Chikarmane SA, Neilsen SS, et al. BI-RADS 3, 4, and 5 lesions: value of US in management - follow-up and outcome. Radiology. 2008;248:773-81

6. Lazarus E, Mainiero MB, Schepps B, et al. BI-RADS lexicon for US and mammography: interobserver variability and positive predictive value. Radiology. 2006;239:385-91.

7. Levy L, Suissa M, Chiche JF, et al. BIRADS ultrasonography. Eur J Radiol. 2007;61:202-11.

8. Calas MJG, Koch HA, Dutra MVP. Ultra-sonografia mamária: avaliação dos critérios ecográficos na diferenciação das lesões mamárias. Radiol Bras. 2007;40:1-7.

9. Hong AS, Rosen EL, Soo MS, et al. BI-RADS for sonography: positive and negative predictive values of sonographic features. AJR Am J Roentgenol. 2005;184:1260-5. 